\title{
Parental presence during pediatric emergency procedures: finding answers in an Asian context
}

\author{
Peter Choong Yi Wong 1,2, Manasvin Tripathi', Aswin Warier' , Zi Ying Lim', \\ Shu-Ling Chong ${ }^{1,2}$
}

'Department of Emergency Medicine, KK Women's and Children's Hospital, Singapore

${ }^{2}$ Duke-NUS Medical School, Singapore

\begin{abstract}
Objective The practice of allowing parental presence during invasive procedures in children varies depending on setting and individual provider preference. We aim to understand the attitudes, preferences, and practices of physicians and nurses with regard to parental presence during invasive pediatric emergency procedures in an Asian cultural context.
\end{abstract}

Methods We surveyed physicians and nurses in the pediatric emergency department of a large tertiary hospital using separate self-administered questionnaires over three months. The data collected included the demographics and clinical experience of interview respondents. Each provider was asked about their attitude and preference regarding parental presence during specific invasive procedures.

Results We surveyed 90 physicians and 107 nurses. Most physicians in our context preferred to perform pediatric emergency procedures without parental presence $(82,91.1 \%)$. Forty physicians (44.4\%) reported that parental presence slowed down procedures, while 75 (83.3\%) felt it increased provider stress. Most physicians made the decision to allow parents into the procedure room based on parental attitude $(69,76.7 \%)$ and the child's level of cooperation $(64,71.1 \%)$. Most nurses concurred that parental presence would add to provider stress during procedures $(69,64.5 \%)$. We did not find a significant relationship between provider experience $(\mathrm{P}=0.26)$ or age $(P=0.50)$ and preference for parental presence.

Conclusion In our cultural context, most physicians and nurses prefer to perform procedures for children in the absence of parents. We propose that this can be changed by health professional training with role play and simulation, adequate supervision by experienced physicians, and clear communication with parents.

Keywords Family; Parents; Pediatric emergency medicine; Asia

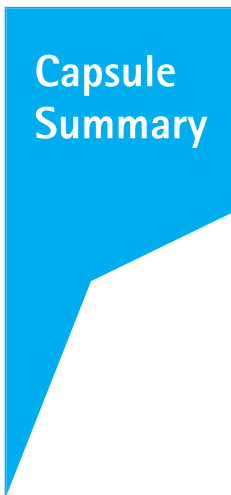

What is already known

There is an increasing emphasis on the role of parents during emergency procedures. The practice of allowing parental presence during invasive procedures varies depending on setting and individual provider preference.

What is new in the current study

The majority of the emergency department physicians and nurses in our setting preferred to perform an invasive procedure without family presence, citing delays in the procedure and unnecessary anxiety. Sick and injured children brought into the emergency department constitute highly charged situations, and more can be done to improve the communication and bridge the expectations between the healthcare provider and the parent.
elSSN: 2383-4625

Received: 20 September 2018

Revised: 7 November 2018

Accepted: 11 December 2018

Correspondence to: Shu-Ling Chong Department of Emergency Medicine, KK Women's and Children's Hospital, 100 Bukit Timah Road, Singapore 229899

E-mail: Chong.Shu-Ling@kkh.com.sg ORCID

http://orcid.org/0000-0003-4647-0019

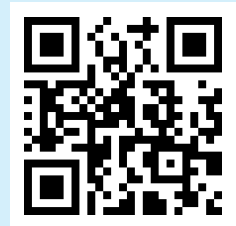

How to cite this article:

Wong CYP, Tripathi M, Warier A, Lim ZY, Chong SL. Parental presence during pediatric emergency procedures: finding answers in an Asian context. Clin Exp Emerg Med 2019;6(4):340-344.

This is an Open Access article distributed under the terms of the Creative Commons Attribution Non-Commercial License (http:// creativecommons.org/licenses/by-nc/4.0/). 


\section{INTRODUCTION}

There has been an increasing emphasis on the role of parents and other caregivers during emergency procedures. The American Heart Association, American Association of Critical Care Nurses, and European Society of Pediatric and Neonatal Intensive Care advocate for the option of family presence during invasive procedures. ${ }^{1,2}$ However, it remains contentious in many settings. ${ }^{3}$

While some studies have reported that the presence of family members during these procedures poses no disruption to clinical care ${ }_{1}^{4-7}$ others have suggested a possible negative impact on the provider's clinical performance. ${ }^{1,3,89}$ Opponents to parental presence have also cited legal issues and loss of learning opportunities for students. ${ }^{9}$ Reluctance to allow parental presence may be greater when the healthcare provider is relatively inexperienced, and when the procedure is more invasive. ${ }^{3,9}$ Medical professionals might oppose parental presence based on preconceptions and beliefs rather than evidence ${ }^{5}$ or might be resistant to changing current practices. ${ }^{6}$

Most existing studies on the topic were conducted in the US. ${ }^{1,2,6-13}$ While we found one study each from Australia ${ }^{5}$ and Europe $_{1}{ }^{14}$ the issue has been largely unexplored in Asia. One study from Thailand looked into parents' willingness to be present during pediatric invasive procedures, ${ }^{4}$ reporting that among 72 children undergoing venipuncture or intravenous cannulation, there was no significant difference in pain response, anxiety level, parental satisfaction, or physician performance when parents were present as compared to when they were not. However, the study did not examine healthcare providers' opinions on parental presence or factors that influenced the decision regarding parental presence during the procedures.

In Singapore, there are no published guidelines on parental presence during pediatric procedures. The authors perceive that practices vary widely, with one extreme being a situation where providers decline to perform a procedure unless the parents leave the room. In this study, we aim to understand the preferences, attitudes, and practices of physicians and nurses with regard to parental presence during pediatric invasive procedures.

\section{METHODS}

\section{Design and setting}

The study was performed from January to March 2016 using an anonymous self-administered questionnaire in the pediatric emergency department (ED) of a women's and children's hospital in Singapore. This ED has an annual census of about 175,000 patients, of which an estimated 25,000 are pediatric trauma patients.
This study was approved by the local institutional review board (2015/3065). In view that this was a survey among healthcare workers, agreement to take part was deemed sufficient for consent and documentation of written informed consent was waived.

\section{Inclusion criteria}

Physicians and nurses in the ED were given separate self-administered questionnaires (Supplementary Materials 1, 2). Doctors of all ranks who work in the ED were invited to participate in this study, including attending physicians, fellows, and residents. Residents included pediatric, emergency medicine, and family medicine residents rotating through the department. Domains of questions for physicians included demographics, specialty (and for the residents, specialty in training), healthcare experience, opinions on the impact of parental presence, and factors that influence their decision to allow parental presence. These influencing factors were divided into three categories: parent, patient, and procedure. Domains of questions for nurses included their opinions on the effect of parental presence on the child, on health professionals, and on the overall procedure being performed. We conducted separate forums for the nurses and doctors where the questionnaires were introduced, and invited clarifications from them.

The procedures in question were venipuncture, insertion of intravenous line, repair of laceration, incision and drainage, foreign body removal, urethral catheterization, and dental repair. Manipulation and reduction of fractures was excluded from the list because this is often performed under fluoroscopic imaging in our setting, wherein family members are requested to wait outside the procedure room in view of radiation risks.

\section{Analysis}

Categorical data were described using frequencies and percentages. Continuous data were described using medians and interquartile ranges. The data were analyzed with IBM SPSS Statistics ver. 23 (IBM Corp., Armonk, NY, USA). Categorical data were analyzed using the chi-square test or Fisher exact test. Continuous data were analyzed using the Wilcoxon rank sum test.

\section{RESULTS}

Ninety responses were received from the physicians and 107 from the nurses. Table 1 depicts the demographic profile of physicians surveyed while Supplementary Material 3 depicts the number of procedures previously performed by the physicians. 
Table 1. Demographics of physicians who responded to the survey $(n=90)$

\begin{tabular}{llc}
\hline Characteristics & & Value \\
\hline Age (yr) & $26-35$ & $67(74.4)$ \\
& $36-45$ & $20(22.2)$ \\
Sex, female & $46-55$ & $3(3.3)$ \\
Race & & $60(66.7)$ \\
& Chinese & $62(68.9)$ \\
& Indian & $10(11.1)$ \\
& Malay & $2(2.2)$ \\
& Caucasian & $2(2.2)$ \\
& Others & $14(15.6)$ \\
Field of specialty/training & Pediatric medicine & $36(40.0)$ \\
& Emergency medicine & $27(30.0)$ \\
& Family medicine & $9(10.0)$ \\
& Others/no specific specialty & $18(20.0)$ \\
& Median postgraduate year of & $6(4-10)$ \\
& practice (interquartile range) & \\
\hline
\end{tabular}

Values are presented as number (\%) unless otherwise indicated.

\section{Physicians' opinions}

The vast majority of physicians surveyed $(82 / 90,91.1 \%)$ preferred to perform procedures without parental presence. This preference for performing procedures without parental presence was consistent across age ranges and years of practice. There was no significant correlation between the age of the physician $(P=0.50)$ or postgraduate year of practice $(P=0.26)$ and the preference for parental presence.

Specific procedures for which physicians were most likely to agree to parental presence were venipuncture $(36 / 90,40 \%)$ and foreign body removal (25/90, 27.8\%). Conversely, 33/90 (36.7\%) were unlikely to agree to parental presence for laceration repair, and 22/90 (24.4\%) for incision and drainage. Factors influencing physicians' decision regarding parental presence were explored in three categories, pertaining to the parent, the patient, and the procedure (Table 2). If either of the patient's parents was a healthcare worker, $46(51.1 \%)$ of the physicians surveyed said they would allow parental presence, 30 (33.3\%) would not, and $14(15.6 \%)$ were unsure. If roles were reversed, 41 (45.6\%) of the physicians surveyed wanted to be present if a procedure was being performed on their own child, whereas 30 (33.3\%) did not want to be present and 19 (21.1\%) were unsure.

\section{Nurses' opinions}

When asked what, from their experience, parents of children undergoing procedures were most worried about, most of the nurses surveyed $(94 / 107,87.9 \%)$ mentioned the child being fretful and uncooperative. Six (5.6\%) thought parents were most worried about inadequate analgesia for the child. Ninety nurses (84.1\%)
Table 2. Most important factors influencing physicians' decisions regarding parental presence

\begin{tabular}{|c|c|}
\hline Factor & Value \\
\hline \multicolumn{2}{|l|}{ Parent } \\
\hline $\begin{array}{l}\text { Parental attitude and posture while receiving the initial expla- } \\
\text { nation of the procedure }\end{array}$ & $71(78.9)$ \\
\hline Parental exposure to a similar experience & $18(20.0)$ \\
\hline Parental education status & $1(1.1)$ \\
\hline \multicolumn{2}{|l|}{ Patient } \\
\hline $\begin{array}{l}\text { Level of fretfulness or cooperation demonstrated by the child } \\
\text { during the initial examination }\end{array}$ & $65(72.2)$ \\
\hline Age of the child & $16(17.8)$ \\
\hline Similar previous experience & $9(10.0)$ \\
\hline \multicolumn{2}{|l|}{ Procedure (top 3) } \\
\hline Predicted difficulty of the procedure & $59(65.6)$ \\
\hline Invasiveness of the procedure & $20(22.2)$ \\
\hline $\begin{array}{l}\text { Location where the procedure is performed (observation area, } \\
\text { resuscitation room, or procedure room) }\end{array}$ & $8(8.9)$ \\
\hline \multicolumn{2}{|l|}{ Physician (top 3) } \\
\hline Experience in performing the particular procedure & $48(53.3)$ \\
\hline Certainty of outcome & $20(22.2)$ \\
\hline Sufficient staff to attend to the parents in the procedure room & $14(15.6)$ \\
\hline
\end{tabular}

Values are presented as number (\%).

said the most common reason parents gave for wanting to remain in the procedure room was to help calm the child by talking to and distracting him/her.

When parental presence was allowed, the experience of the majority of nurses $(56 / 107,52.3 \%)$ was that most parents were supportive and consoled or soothed the child. Twenty-one (19.6\%) reported that parents were aggressive or anxious, 16 (15.0\%) reported that parents were emotional and cried, and 13 (12.1\%) reported that parents remained passive. Most nurses (69/107, $64.4 \%$ ) perceived physician discomfort or distraction as the usual effect of parental presence during a procedure, whereas 26 (24.3\%) felt that physicians were usually unaffected. Eleven nurses $(10.3 \%)$ felt that physicians usually worked better with parents present.

Table 3 depicts the nurses' perceptions of how a child usually fares with and without parental presence during a procedure. Table 4 presents both physicians' and nurses' opinions on the effect of parental presence during procedures. If a procedure was to be performed on their own child, $40(37.4 \%)$ of the nurses would want to be present, 41 (38.3\%) would not, and 26 (24.3\%) were unsure.

\section{DISCUSSION}

In our study, the majority of the physicians and nurses preferred to perform invasive procedures in children without parental presence, citing increased stress levels and prolonged duration of pro- 
Table 3. Nurses' perception of how a child usually fares with and without parental presence during a procedure

\begin{tabular}{lcc}
\hline $\begin{array}{l}\text { Nurses' perception } \\
\begin{array}{l}\text { Child is calm/easily distractible from the } \\
\text { beginning }\end{array}\end{array}$ & $\begin{array}{c}\text { With parental } \\
\text { presence }\end{array}$ & $\begin{array}{c}\text { Without parental } \\
\text { presence }\end{array}$ \\
$\begin{array}{l}\text { Child is initially fretful then settles down } \\
\text { and the procedure is completed }\end{array}$ & $11(10.3)$ & $71(66.4)$ \\
$\begin{array}{l}\text { Child is fretful throughout the procedure, } \\
\text { but the procedure is still completed }\end{array}$ & $83(77.6)$ & $33(30.8)$ \\
$\begin{array}{l}\text { Child is fretful throughout the procedure, } \\
\text { resulting in the procedure being } \\
\text { discontinued }\end{array}$ & $10(9.3)$ & $1(0.9)$ \\
\hline
\end{tabular}

Values are presented as number (\%).

cedure. Physicians indicated that they were more likely to allow parental presence for less invasive procedures such as venipuncture. Even though parental presence has been advocated by major health organizations globally, many institutions still do not have clear guidelines on this practice. One survey of 984 ED and critical care nurses in the USA showed that only 5\% worked in units that have a clear written policy allowing parental presence. ${ }^{10}$

The effect of parental presence is deeply contextual and dependent on social and cultural factors. Previous reports have suggested that family members who are anxious about the procedure may interfere by asking multiple questions, misinterpret treatment activities, or divert the doctor's attention away from the child. ${ }^{1,8}$ In our study, the nurses reported that some parents who were allowed to stay in the procedure room were anxious or aggressive, while some others became emotional or cried. These behaviors may have a distracting and disruptive effect on the procedure. We postulate that the reluctance of our health professionals to allow parental presence may be a response to commonly seen reactions of parents in our social context. To overcome these difficulties, Sacchetti et al.? recommended that medical professionals practice to get used to parental presence through role playing and observation experiences. Medical and nursing students can likewise be trained for parental presence through simulation scenarios. The fact that there was a relatively large proportion of doctors-in-training among our physician respondents may have influenced our findings. Senior doctors would likely be more willing to allow parental presence compared to doctors-in-training. ${ }^{9}$ Our study did not show a statistically significant relationship between physician experience and preference for parental presence, but this might have been due a lack of statistical power, given the very small overall number of physicians who preferred parental presence. We believe that such anxiety can be partly ameliorated by building interaction skills with parents and other family members as an important component of
Table 4. Physicians' and nurses' opinions on the effect of parental presence on physician efficiency, stress level, and time needed to complete the procedure

\begin{tabular}{|c|c|c|c|c|}
\hline Opinion & $\begin{array}{c}\text { Strongly } \\
\text { disagree/disagree }\end{array}$ & $\begin{array}{c}\text { Neither agree } \\
\text { nor disagree }\end{array}$ & Agree & $\begin{array}{c}\text { Strongly } \\
\text { agree }\end{array}$ \\
\hline \multicolumn{5}{|c|}{ Negative effect on physician's efficiency } \\
\hline Physicians & $10(11.1)$ & $32(35.6)$ & $32(35.6)$ & $16(17.8)$ \\
\hline Nurses & $18(16.8)$ & $37(34.6)$ & $34(31.8)$ & $18(16.8)$ \\
\hline \multicolumn{5}{|c|}{ More time needed } \\
\hline Physicians & $15(16.7)$ & 35 (38.9) & $33(36.7)$ & $7(7.8)$ \\
\hline Nurses & $11(10.2)$ & $21(19.6)$ & $39(36.4)$ & $36(33.6)$ \\
\hline \multicolumn{5}{|c|}{ Additional stress } \\
\hline Physicians & $4(4.4)$ & $11(12.2)$ & $43(47.8)$ & $32(35.6)$ \\
\hline Nurses & $10(9.3)$ & $16(15.0)$ & $39(36.4)$ & $42(39.3)$ \\
\hline
\end{tabular}

Values are presented as number (\%).

residency training.

There are numerous benefits of supervision by a more experienced colleague while performing a procedure with parental presence: the trainee builds competence in the procedural skill, at the same time learns by observing the interaction of the senior doctor with the parents, and also gains confidence. The parents are more reassured and can also appreciate the culture of learning in healthcare institutions. Other opposers to parental presence have also cited that students' learning opportunities may be lost if anxious parents present at procedures object to the students' involvement. ${ }^{9}$ This can be overcome by laying out clear expectations in academic institutions, with written communication to patients and their families, where a culture of learning is established as the norm and accepted by all who receive care from the institution. As hospitals aim to provide family-centered care, allowing parents to be present to support their child during a procedure is a positive step for the greater welfare and dignity of both patients and family members. Clear communication, to help parents understand their roles and responsibilities during a procedure, would be needed. The presence of a dedicated patient care assistant to attend to the questions and needs of parents or family members may allow nurses and physicians to focus on the child and perform the procedure efficiently.

We recognize the limitations of our study. This was a singlecenter study, with a large proportion of young doctors working in the ED. Statistical power was limited by the small number of physicians in favor of parental presence. We recognize that these results may not be generalizable to other healthcare settings with different sociocultural contexts. The true value of parental presence can only be examined in a comparison study between interventions performed with parental presence and those without parental presence, taking not only healthcare providers' opinions 
but also parents' and patients' satisfaction into account.

In conclusion, we report that most physicians and nurses in our setting prefer invasive procedures for children to be performed in the absence of family, believing that parental presence contributes to provider stress and treatment delays. It is vitally important to address these concerns of health professionals even as we strive to optimize the care of sick and injured children in the ED. Patients, families, and health professionals all stand to benefit from improved communication, increased mutual trust, and bridging of expectations.

\section{CONFLICT OF INTEREST}

No potential conflict of interest relevant to this article was reported.

\section{ACKNOWLEDGMENTS}

We would like to thank the doctors and nurses in the Department of Emergency Medicine, KK Women's and Children's Hospital, Singapore, for participating in this survey.

\section{SUPPLEMENTARY MATERIAL}

Supplementary Materials are available from: $h t t p s: / / d o i . o r g / 10.15441 /$ ceem.18.075.

\section{REFERENCES}

1. Dingeman RS, Mitchell EA, Meyer EC, Curley MA. Parent presence during complex invasive procedures and cardiopulmonary resuscitation: a systematic review of the literature. Pediatrics 2007;120:842-54.

2. Meyers $T A$, Eichhorn DJ, Guzzetta $C E$, et al. Family presence during invasive procedures and resuscitation. Am J Nurs 2000; 100:32-42.

3. Piira T, Sugiura T, Champion GD, Donnelly N, Cole AS. The role of parental presence in the context of children's medical procedures: a systematic review. Child Care Health Dev 2005;31:
233-43.

4. Tantikul C, Theeranate C. Effect of parental presence while children undergo common invasive procedures. J Med Assoc Thai 2014;97 Suppl 2:S153-8.

5. Ryan G, Treston G. Do family members interfere in the delivery of care when present during invasive paediatric procedures in the emergency department? Emerg Med Australas 2007;19: 234-40.

6. Beckman AW, Sloan BK, Moore GP, et al. Should parents be present during emergency department procedures on children, and who should make that decision? A survey of emergency physician and nurse attitudes. Acad Emerg Med 2002; 9:154-8.

7. Sacchetti A, Carraccio C, Leva E, Harris RH, Lichenstein R. Acceptance of family member presence during pediatric resuscitations in the emergency department: effects of personal experience. Pediatr Emerg Care 2000;16:85-7.

8. Nishisaki A, Diekema DS. Mind the gap and narrowing it: family presence during pediatric resuscitation and invasive procedures. Resuscitation 2011;82:655-6.

9. Fein JA, Ganesh J, Alpern ER. Medical staff attitudes toward family presence during pediatric procedures. Pediatr Emerg Care 2004;20:224-7.

10. Maclean SL, Guzzetta CE, White $C$, et al. Family presence during cardiopulmonary resuscitation and invasive procedures: practices of critical care and emergency nurses. J Emerg Nurs 2003;29:208-21.

11. Mangurten JA, Scott SH, Guzzetta $C E$, et al. Family presence: making room. Am J Nurs 2005;105:40-8.

12. Bauchner H, Waring C, Vinci R. Parental presence during procedures in an emergency room: results from 50 observations. Pediatrics 1991;87:544-8.

13. Bradford KK, Kost $S$, Selbst SM, Renwick AE, Pratt A. Family member presence for procedures: the resident's perspective. Ambul Pediatr 2005;5:294-7.

14. Vavarouta A, Xanthos T, Papadimitriou L, Kouskouni E, lacovidou N. Family presence during resuscitation and invasive procedures: physicians' and nurses' attitudes working in pediatric departments in Greece. Resuscitation 2011;82:713-6. 